\title{
Vasogenic origin of visual field defects and optic nerve changes in glaucoma
}

\author{
S. S. HAYREH, I. H. S. REVIE, AND J. EDWARDS \\ Department of Experimental Ophthalmology, Institute of Ophthalmology, University of London
}

Many authors have speculated upon the possibility of a vasogenic origin for the visual field defects, optic disc cupping, and cavernous degeneration in glaucoma, but the exact mechanism has remained obscure. In our recent experimental studies (Hayreh and Perkins, I968, I969; Hayreh, 1969) we discovered the important role of the ciliary circulation, particularly the contribution of the choroidal circulation to the prelaminar part of the optic disc and the retrolaminar part of the optic nerve.

In fluorescein fundus angiographies the choroidal vascular bed and its contribution to the optic disc are normally masked by the overlying dense retinal vascular bed. In our previous studies to assess the choroidal circulation and the changes therein which are associated with ocular hypertension, the retinal circulation was experimentally occluded in one eye of a cynomolgus monkey and the findings reported as a part of other investigations (Hayreh and Perkins, 1969; Hayreh, 1969). This method has since been employed in a further series of experiments and has provided further information on the subject.

\section{Material and methods}

In eight eyes of five cynomolgus monkeys the central retinal artery was exposed by lateral orbitotomy and occluded near its site of entry into the optic nerve. Fluorescence fundus angiography was then performed after an injection of $0.15 \mathrm{ml}$. 5 per cent. sodium fluorescein solution into the common carotid artery on the same side. The fundus was photographed every $0.8 \mathrm{sec}$. by a Zeiss fundus camera adapted for fluorescence angiography, starting from the time of injection of the dye and continuing until the end of the transit of the dye.

Fluorescence fundus angiographies were repeated on five eyes at normal intraocular pressure and at pressures of 70,30 , and $15 \mathrm{~mm}$. $\mathrm{Hg}$ (Fig. I). In one animal fluorescence angiography was first performed in the left eye at the normal intraocular pressure (about $12 \mathrm{~mm} . \mathrm{Hg}$ ) and at 70 and $40 \mathrm{~mm}$. $\mathrm{Hg}$ (Fig. 2); and then in the right eye at the same intraocular pressures (Fig. 3). The systemic arterial blood pressure was then lowered rapidly by the intravenous injection of Lignocaine solution and fluorescence angiography was repeated in the right eye at intraocular pressures of 70,40 , and $20 \mathrm{~mm}$. Hg (Fig. 3). The blood pressure was allowed to recover to $\mathrm{I}$ 1 $/ 60 \mathrm{~mm}$. $\mathrm{Hg}$ and fluorescence angiography was repeated at an intraocular pressure of $15 \mathrm{~mm} . \mathrm{Hg}$ in the right eye.

In another monkey, in which the blood pressure had fallen to $35 / 15 \mathrm{~mm}$. Hg owing to surgical shock, fluorescence angiography was performed in the right eye at the normal intraocular pressure, 50,20 , and $5 \mathrm{~mm}$. $\mathrm{Hg}$.

The systemic blood pressure was measured by cannulating the femoral artery in two animals ( 3 eyes), and was recorded on a Sanborn recorder. 
(a)

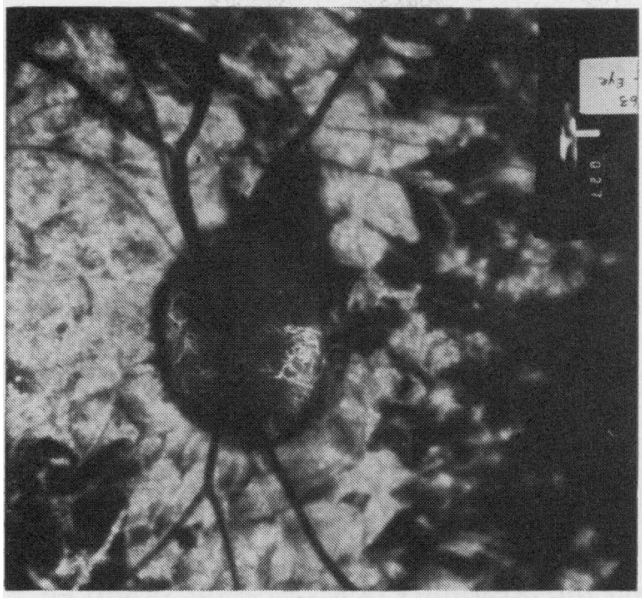

(c)

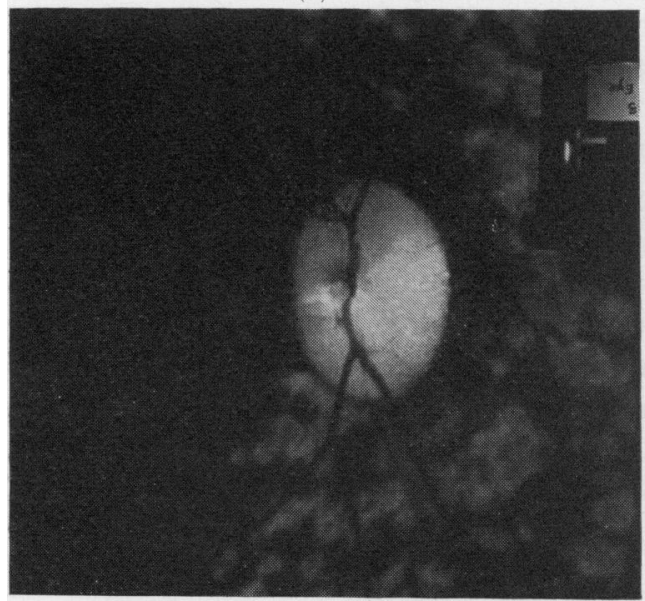

(b)

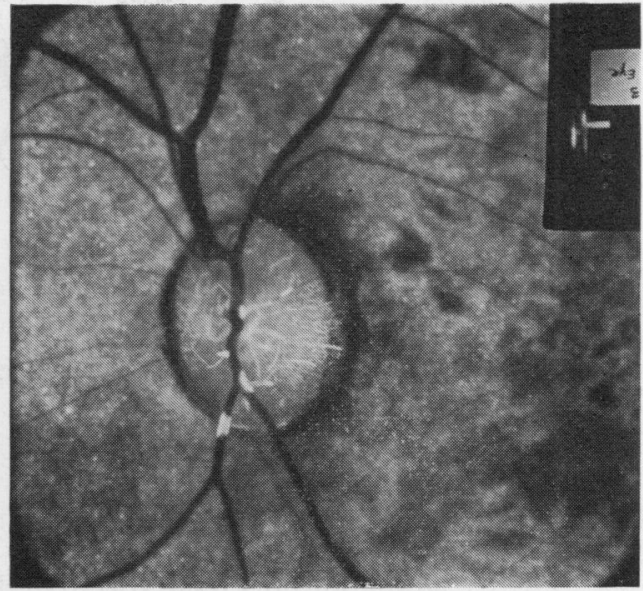

(d)

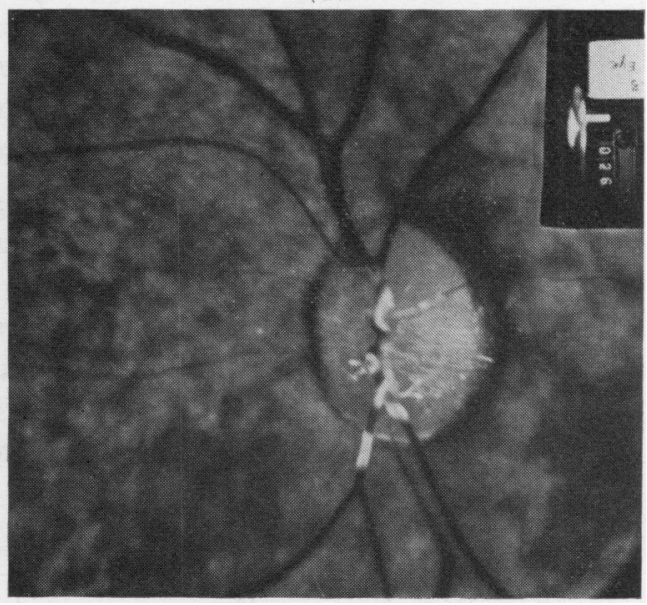

FIG. I Fluorescence fundus angiograms of left eye of a cynomolgus monkey (after experimental central retinal occlusion) at normal (a, b), $70 \mathrm{~mm} . \mathrm{Hg}(\mathrm{c})$, and $30 \mathrm{~mm} . \mathrm{Hg}$ (d) intraocular pressures

(b), (c), and (d) are comparable phases of circulation of the dye at three intraocular pressures

(a) and (b) are at $\mathrm{i} .6 \mathrm{sec}$. interval, showing pattern of filling of vessels in choroid and optic disc. Choroidal pigment deposit at disc margins obscures underlying choroidal fluorescence in some places

\section{Observations}

In all these fluorescence angiographies the pattern of filling of the choroid in the posterior segment, the peripapillary choroid, and the optic disc was recorded. The results fall into two categories:

(A) Seven eyes of animals with normal or apparently normal blood pressure.

(B) Two eyes of animals in which the systemic arterial blood pressure was very low.

\section{(A) Normal systemic arterial pressure}

(I) GHOROID

In most cases the choroidal circulation shows marked variations in the degree of filling. This makes the interpretation of its circulation by fluorescence fundus angiography very 
(a)

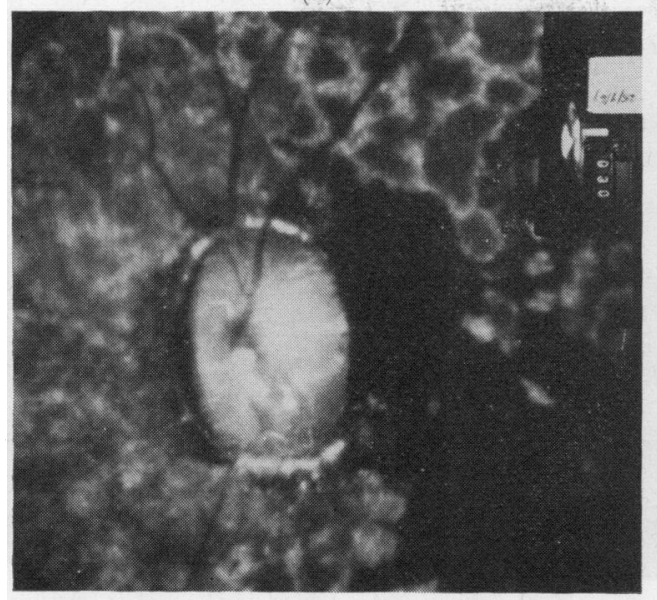

(c)

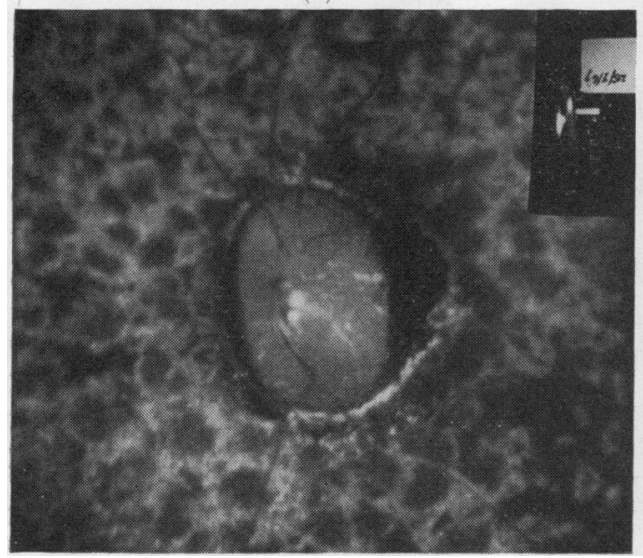

(b)

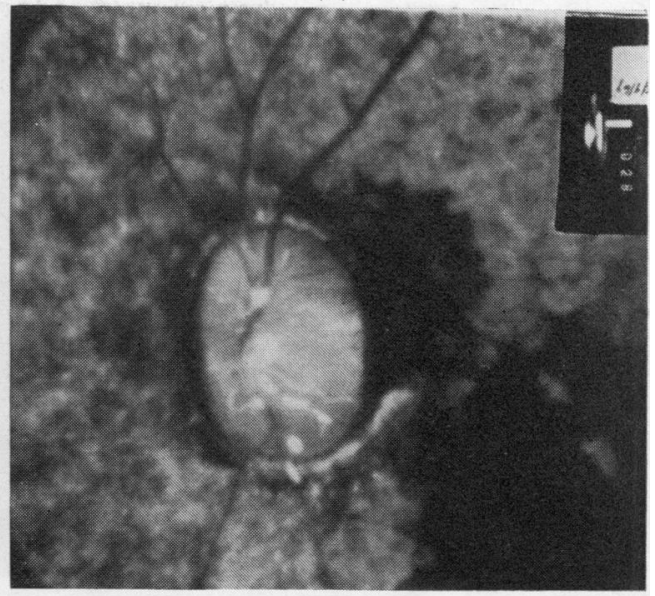

(d)

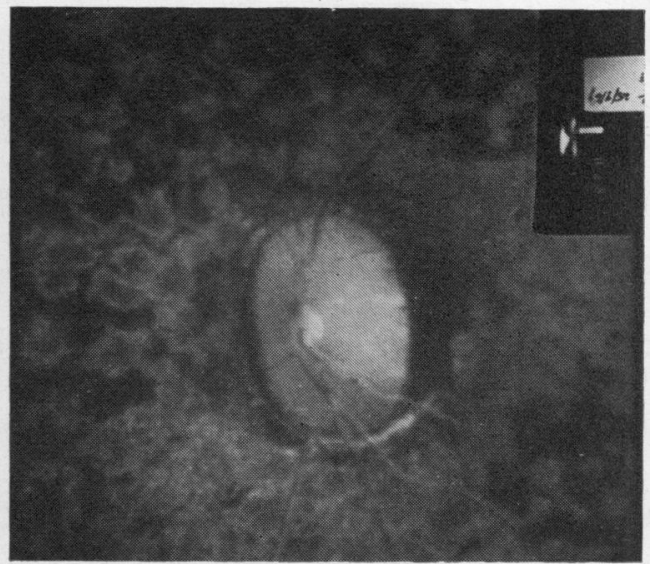

FIG. 2 Fluorescence fundus angiograms of left eye of a cynomolgus monkey (after exprimental central retinal occlusion) at normal (a, b), $70 \mathrm{~mm}$. $\mathrm{Hg}$ (c), and $85 \mathrm{~mm}$. $\mathrm{Hg}$ (d) intraocular pressures

(e) shows tracings of systemic arterial blood pressures at three intraocular pressures, i.e. I 5o/85 mm. $\mathrm{Hg}$

(b), (c), and (d) are comparable phases of circulation of the dye at the three intraocular pressures

(a) and (b) are at $0.8 \mathrm{sec}$. interval

(e)

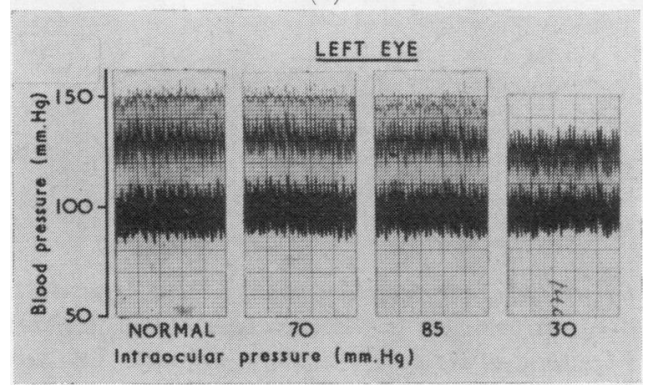

Filling defect in temporal peripapillary choroid is a spatial variation

Choroidal pigment deposit at disc margins obscures fluorescence in some areas

difficult, and sometimes erroneous, if a single picture only or a series of pictures taken at prolonged intervals is examined. A series of angiograms taken in quick succession, however, quite often reveals a changing pattern of choroidal filling from picture to picture. 
(a)

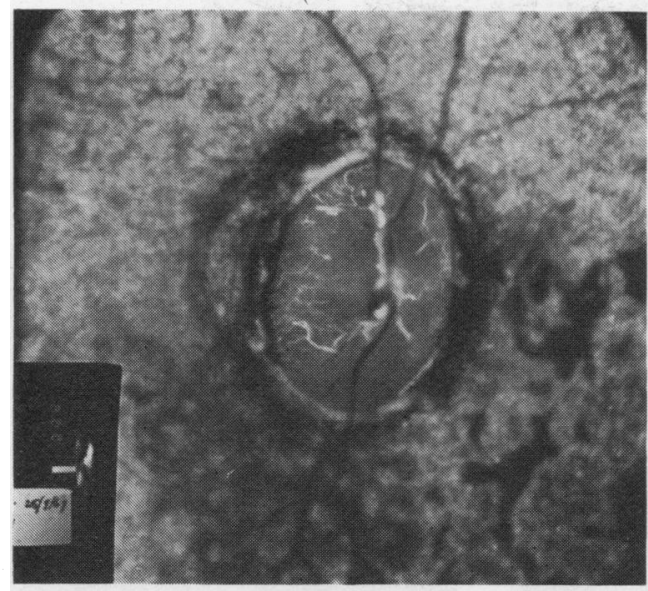

(c)

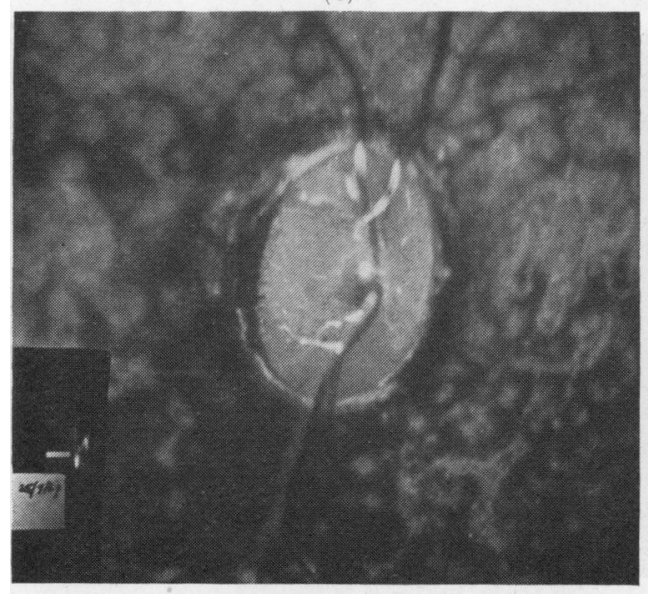

(e) (b)

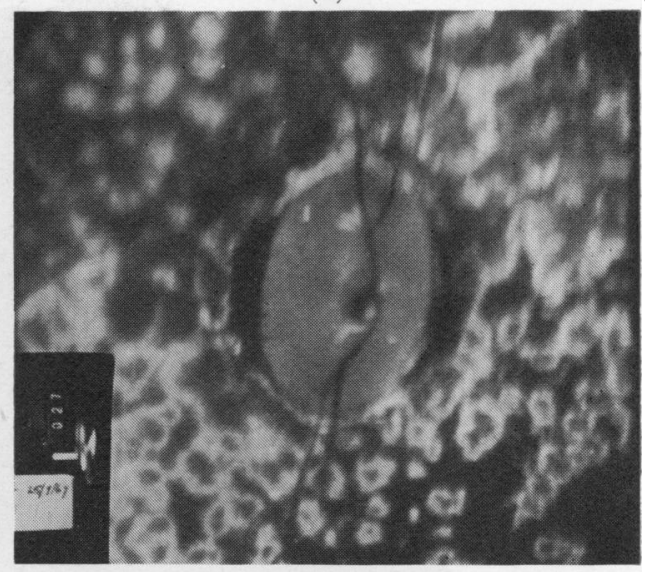

(d)

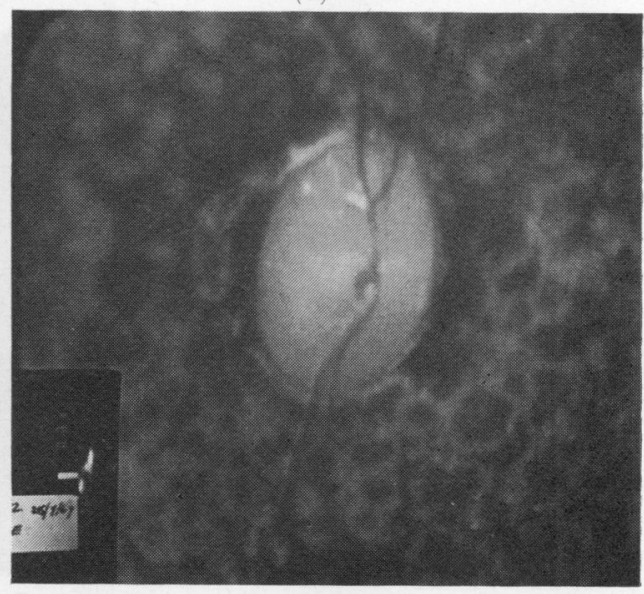

W

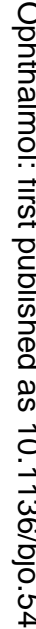

iे

묵

윽

产

ঢิ

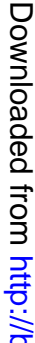
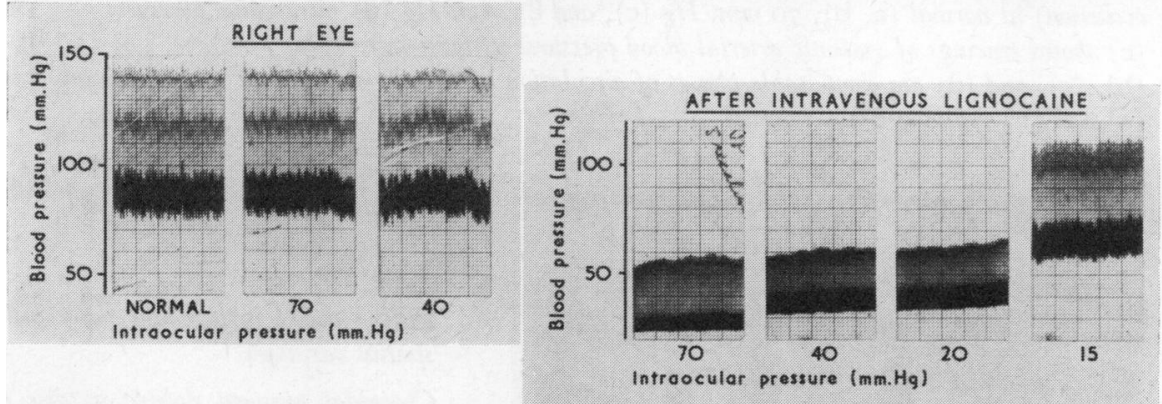

FIG. 3 Fluorescence fundus angiograms of right eye of a cynomolgus monkey (after experimental central retinal artery occlusion) at normal (a), $70 \mathrm{~mm}$. $\mathrm{Hg}$ (b), $40 \mathrm{~mm}$. $\mathrm{Hg}$ (c), and $20 \mathrm{~mm}$. $\mathrm{Hg}$ (d) intraocular pressures (e) shows tracings of systemic arterial blood pressures at the three intraocular pressures, i.e. $140 / 80 \mathrm{~mm} . \mathrm{Hg}$ at (a) and (b), 140/75 mm. $\mathrm{Hg}$ at (c), and $62 / 35 \mathrm{~mm}$. $\mathrm{Hg}$ at (d)

Choroidal pigment deposit at disc margins obscures underlying fluorescence in some areas All pictures represent comparable phases of circulation at the various intraocular pressures 
(a)

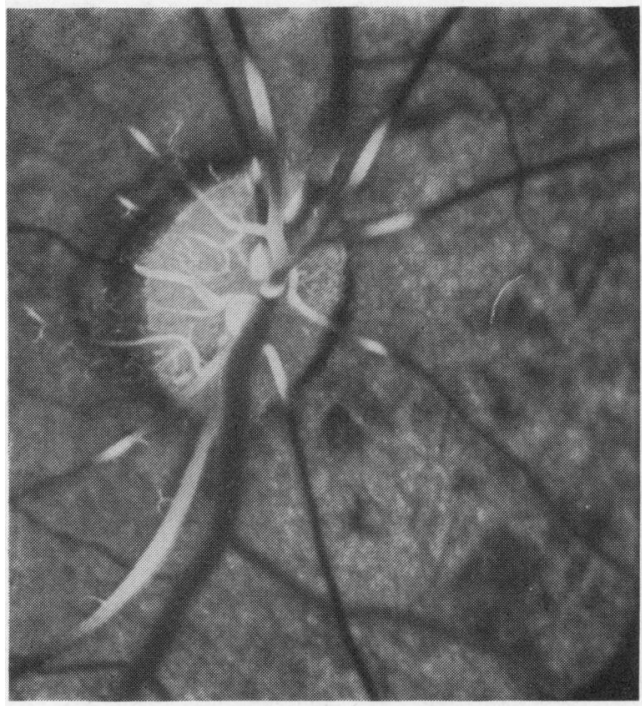

(b)

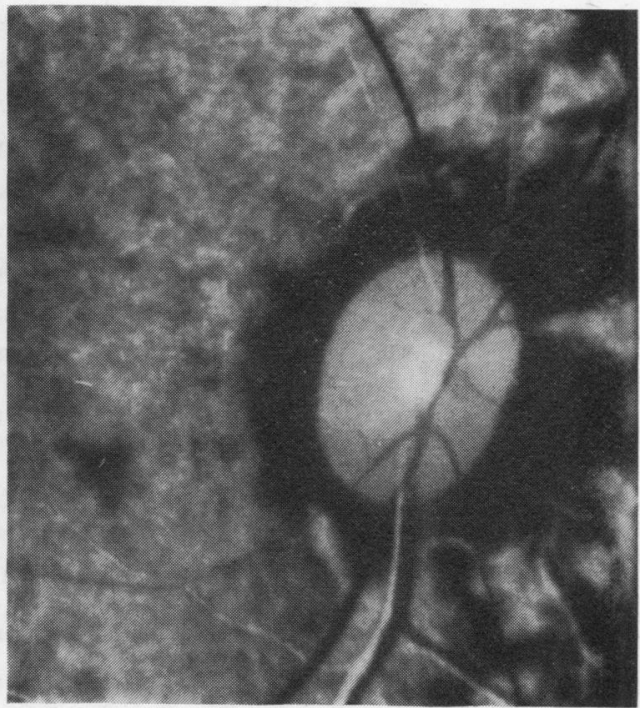

FIG. 4 Fluorescence fundus angiograms of right eye of a cynomolgus monkey (after experimental central retinal artery occlusion) at normal (a) and $70 \mathrm{~mm} . \mathrm{Hg}$ (b) intraocular pressures

Choroidal pigment deposit at disc margins obscures underlying fuorescence in some areas

The appearances after an interval of a few seconds, or even after $0.8 \mathrm{sec}$, may show a reversal of the filling pattern. The true pattern of choroidal filling can therefore be assessed only by examining the entire transit of the dye in the choroid photographed serially at very short intervals. Many of the variations in the filling of the choroid may be classified as spatial or temporal variations. In the former some areas fill first and empty first, while others fill later and empty later. Temporal variation, in which different transits of the dye show different patterns of choroidal filling, is common. In addition to these variations, rapid serial photography at $0.8 \mathrm{sec}$. intervals often shows that some areas fill and empty more rapidly than others.

(a) At the normal intraocular pressure The whole of the choroid filled (Figs $1 b, 3 a, 4 a$ ), though spatial variations were seen in the majority of the eyes, i.e. some parts filled earlier and emptied earlier than others. The peak filling of the choroid and its maximum fluorescence were usually reached in about 3 to $4 \mathrm{sec}$, , rarely after longer intervals.

(b) At $70 \mathrm{~mm}$. $\mathrm{Hg}$ intraocular pressure There was delay in filling of the choroid and the transit time of the dye was prolonged. The filling tended at first to have a honeycomb pattern and was sometimes patchy (Figs $\mathrm{I} c, 2 c, 3^{b}$ ); at peak filling, however, the fluorescence was usually denser than at the normal intraocular pressure, presumably because of marked venous congestion. Spatial variations in filling were still present. In two out of eight eyes the watershed areas between the distribution of the two main posterior ciliary arteries did not fill at this pressure (see Fig. 12b in Hayreh, 1969).

In an eye in which the intraocular pressure was raised to $85 \mathrm{~mm}$. $\mathrm{Hg}$ (Fig. 2d), with the systemic blood pressure at $150 / 85 \mathrm{~mm}$. $\mathrm{Hg}$, these changes in the choroid were more pronounced than at $70 \mathrm{~mm}$. $\mathrm{Hg}$ (Fig. 2c) in the same eye, i.e. there was slower filling with a longer transit time and denser fluorescence. 
(c) At $30 \mathrm{~mm}$. $\mathrm{Hg}$ intraocular pressure The filling and emptying of the choroid was slightly slower than at the normal pressure in the same eye, but much faster than at $70 \mathrm{~mm}$. $\mathrm{Hg}$. The honeycomb pattern was less marked than at $70 \mathrm{~mm}$. $\mathrm{Hg}$ (Fig. I $d$ ). The filling defect seen in the watershed areas in the two eyes at $70 \mathrm{~mm}$. $\mathrm{Hg}$ was not seen at this pressure. In two eyes in animals with systemic blood pressures of $140 / 75$ and $130 / 85 \mathrm{~mm}$. $\mathrm{Hg}$, no significant change in the choroid was detected at this pressure and filling was almost the same as at the normal intraocular pressure. Spatial variations in the filling were seen.

(2) PERIPAPILLARY CHOROID The different types of variation in the filling of the choroid were also seen in the peri- $\frac{\overrightarrow{\vec{\omega}}}{\mathrm{\omega}}$
papillary choroid (p. 462).

(a) At the normal intraocular pressure The peripapillary choroid filled well (Figs $\mathrm{I} b, 3 a, 4 a$ ). ํㅡㄴ Four eyes, however, showed a poor and late filling of one portion:

(i) In the upper and lower parts in two eyes;

(ii) In the infero-nasal part in one eye;

(iii) In the supero-nasal part in one eye.

(b) At $70 \mathrm{~mm}$. $\mathrm{Hg}$ intraocular pressure Filling defects in the peripapillary choroid were $\overrightarrow{0}$ seen in four of six eyes, in which a detailed examination of this region was possible. In the other two eyes the systemic blood pressure was in the region of $140 / 80 \mathrm{~mm}$. $\mathrm{Hg}$. The distribution of the filling defects in the peripapillary choroid was as follows:

(i) No filling of the peripapillary choroid above, below, and nasal to the optic disc in one eye;

(ii) No filling of the entire peripapillary choriod all round the optic disc in one eye (Fig. $4 b$ );

(iii) No filling of the peripapillary choroid except in the supero-temporal sector in one eye;

(iv) No filling of the temporal part of the peripapillary choroid in one eye (Fig. 2c). This eye had some peripapillary choroidal atrophy in this sector. At the normal intraocular pressure, however, it filled normally, though it showed a spatial variation in the temporal region.

(c) At $30 \mathrm{~mm}$. Hg intraocular pressure Complete obliteration of the peripapillary choroid was not seen at this intraocular pressure (Fig. Id). In four out of six eyes some sectors showed late filling with rapid emptying:

(i) The entire peripapillary choroid;

(ii) The lower part of the peripapillary choroid;

(iii) The area round the optic disc, except in the temporal part;

(iv) The nasal part of the peripapillary choroid.

(3) OPTIG DISG

(a) At the normal intraocular pressure The entire disc filled, with the temporal sector containing the maculo-papillar bundle region showing the maximum fluorescence in all $\stackrel{?}{?}$

the bundles (Figs I $a, b, 2 a, b, 3 a, 4 a$ ).
In one eye the temporal part of the peripapillary choroid filled very late (Figs $2 a, b$ ); the temporal sector of the disc, however, filled earlier and normally, which indicated that, in this eye, the temporal region of the disc probably filled mainly from the vessels of the underlying lamina cribrosa or possibly from a peripapillary vessel which could not be 
seen because of overlying pigment. This possible explanation is suggested because in some eyes a circular vessel was outlined round the optic disc.

Fluorescence of the optic disc usually developed in parallel with the choroidal flourescence.

(b) At $70 \mathrm{~mm}$. $\mathrm{Hg}$ intraocular pressure The filling of vessels in the optic disc was very much reduced at this pressure. In two eyes no vessels filled at all (Fig. $4 b$ ); in three eyes there was delayed and very poor filling, and that only in the temporal sector (Fig. Ic); in the remaining two the temporal and nasal parts filled-the temporal more than the nasalbut it was a poor and late filling (Fig. 2c, $3 b$ ). In these two animals, the systemic arterial blood pressure was $150 / 85$ and $140 / 80 \mathrm{~mm}$. $\mathrm{Hg}$ respectively. In one of them, when the intraocular pressure was raised to $85 \mathrm{~mm}$. $\mathrm{Hg}$ (with systemic arterial blood pressure at I $50 / 85 \mathrm{~mm}$. $\mathrm{Hg}$ ), only the vessels in the temporal sector filled, and even these filled late and very poorly (Fig. $2 d$ ).

Fluorescence of the optic disc usually developed in parallel with the choroidal fluorescence.

(c) At $30 \mathrm{~mm}$. $\mathrm{Hg}$ intraocular pressure The vessels of the optic disc filled well but slightly less than at the normal intraocular pressure (Fig. I $d,{ }_{3} c$ ). In a few instances there was no significant difference from the filling at the normal intraocular pressure.

\section{(B) Low systemic arterial pressure}

In one animal experimental systemic arterial hypotension was induced by the intravenous injection of Lignocaine solution; the filling of the choroid, peripapillary choroid, and the optic disc in the right eye at different intraocular pressures is shown in Table I.

Table I Pattern of filling of vessels of choroid and optic disc in right eye of a cynomolgus monkey at different intraocular pressures and systemic arterial blood pressures

\begin{tabular}{|c|c|c|c|c|c|}
\hline \multirow{2}{*}{$\begin{array}{l}\text { Fluorescein } \\
\text { angio- } \\
\text { graphy } \\
\text { transit no. }\end{array}$} & \multicolumn{2}{|c|}{ Pressures $(m m . H g)$} & \multicolumn{3}{|l|}{ Filling of } \\
\hline & $\begin{array}{l}\text { Systemic } \\
\text { arterial }\end{array}$ & $\begin{array}{l}\text { Intra- } \\
\text { ocular }\end{array}$ & Choroidal vessels & $\begin{array}{l}\text { Peripapillary } \\
\text { choroidal } \\
\text { vessels }\end{array}$ & Optic disc vessels \\
\hline (Fig. 3a) & $140 / 80$ & Normal & $\begin{array}{l}\text { Whole choroid filled } \\
\text { Maximum in } 3 \text { rd exposure }\end{array}$ & Normal & Whole disc filled \\
\hline $\begin{array}{l}\text { II } \\
\text { (Fig. } 3^{b} \text { ) }\end{array}$ & $140 / 80$ & 70 & $\begin{array}{l}\text { Slow with delayed transit } \\
\text { Maximum in } 7-8 \text { th exposure }\end{array}$ & $\begin{array}{l}\text { No significant } \\
\text { defect } \\
\text { Delayed }\end{array}$ & $\begin{array}{l}\text { Poor and slow } \\
\text { Temporal side only filled }\end{array}$ \\
\hline $\begin{array}{l}\text { III } \\
\text { (Fig. } 3 c)\end{array}$ & $140 / 75$ & 40 & $\begin{array}{l}\text { Whole choroid filled } \\
\text { Maximum in } 6 \text { th exposure } \\
\text { Transit slightly more } \\
\text { prolonged than at normal } \\
\text { intraocular pressure }\end{array}$ & $\begin{array}{l}\text { No significant } \\
\text { defect }\end{array}$ & $\begin{array}{l}\text { Slightly less than } \\
\text { normal but much better } \\
\text { than at } 70 \mathrm{~mm} . \mathrm{Hg}\end{array}$ \\
\hline IV & $57 / 25$ & 70 & None & None & None \\
\hline V & $60 / 32$ & 40 & None & None & None \\
\hline $\begin{array}{l}\text { VI } \\
\left.\text { (Fig. } 3^{d}\right)\end{array}$ & $62 / 35$ & 20 & Very similar to II & & \\
\hline VII & $110 / 60$ & I5 & $\begin{array}{l}\text { Rapid filling of whole choroid } \\
\text { Maximum in 3rd exposure } \\
\text { Shorter transit time than in I }\end{array}$ & No defect & $\begin{array}{l}\text { Difficult to assess owing } \\
\text { to marked fluorescence } \\
\text { of optic disc by this } \\
\text { stage }\end{array}$ \\
\hline
\end{tabular}


In the second animal, in which the systemic arterial pressure was $35 / 15 \mathrm{~mm}$. $\mathrm{Hg}$, the choroid and optic disc showed normal filling at normal intraocular pressure, but there was no filling of the choroid and disc at intraocular pressures of $5^{\circ}$ and $25 \mathrm{~mm}$. $\mathrm{Hg}$. When the intraocular pressure was lowered to $5 \mathrm{~mm}$. $\mathrm{Hg}$ the choroid and disc filled normally (Table II).

Table II Pattern of filling of vessels of choroid and optic disc in three eyes of two cynomolgus monkeys (Nos I and 2 belonging to one animal) at different intraocular pressures and systemic arterial blood pressures

\begin{tabular}{|c|c|c|c|c|c|}
\hline \multirow[b]{2}{*}{ Eye no. } & \multicolumn{3}{|c|}{ Pressures $(\mathrm{mm} . \mathrm{Hg})$} & \multicolumn{2}{|l|}{ Filling of } \\
\hline & $\begin{array}{l}\text { Systemic } \\
\text { arterial }\end{array}$ & $\begin{array}{l}\text { Ophthalmic } \\
\text { arterial }\end{array}$ & Intraocular & Choroidal vessels & Optic disc vessels \\
\hline \multirow[t]{3}{*}{ I } & I $50 / 85$ & $110 / 75$ & $\stackrel{70}{\text { (Fig. 2c) }}$ & Slow with prolonged transit & $\begin{array}{l}\text { Less than normal } \\
\text { Temporal > nasal }\end{array}$ \\
\hline & $150 / 85$ & $110 / 75$ & $\begin{array}{l}85 \\
(\text { Fig. } 2 d)\end{array}$ & $\begin{array}{l}\text { Still slower with more } \\
\text { prolonged transit }\end{array}$ & $\begin{array}{l}\text { Very poor } \\
\text { Some vessels filled in } \\
\text { temporal part only }\end{array}$ \\
\hline & $150 / 85$ & $110 / 75$ & 30 & Normal with normal transit & Normal \\
\hline \multirow{6}{*}{$\begin{array}{l}2 \\
\text { (See also } \\
\text { Table I) }\end{array}$} & $140 / 80$ & $100 / 72$ & $\left.\stackrel{70}{(\text { Fig. }} 3^{b}\right)$ & Slow with prolonged transit & $\begin{array}{l}\text { Poor } \\
\text { Only temporal side filled }\end{array}$ \\
\hline & $140 / 75$ & $100 / 68$ & $\stackrel{40}{(\text { Fig. } 3 c)}$ & Slightly less than normal & Slightly less than normal \\
\hline & $57 / 25$ & $42 / 22$ & 70 & None & None \\
\hline & $60 / 32$ & $44 / 29$ & 40 & None & None \\
\hline & $62 / 35$ & $45 / 31$ & $\stackrel{20}{\left(\text { Fig. } 3^{d}\right)}$ & Slow with delayed transit & $\begin{array}{l}\text { Poor } \\
\text { Only temporal side filled }\end{array}$ \\
\hline & $110 / 60$ & $80 / 54$ & 15 & Normal & $\begin{array}{l}\text { Difficult to assess owing to } \\
\text { marked fluorescence of } \\
\text { optic disc }\end{array}$ \\
\hline \multirow[t]{3}{*}{3} & $35 / 15$ & $25 / 13$ & 50 & None & None \\
\hline & $35 / 15$ & $25 / 13$ & 25 & None & None \\
\hline & $35 / 15$ & $25 / 13$ & 5 & Normal & Normal \\
\hline
\end{tabular}

\section{Discussion}

Duke-Elder (1953), stressing the vasogenic factor in glaucoma, stated that "if the be-all and end-all of glaucoma resided in a raised tension and the raised tension itself were dependent upon the efficacy of drainage of the intraocular fluids, then surely the anxietiesc of five generations of ophthalmologists and the tragedy of blindness that has overtaken countless numbers of their patients could be mechanically relieved by sufficiently enthu- 0 siastic surgery". Moreover, Duke-Elder (i955) reported that glaucomatous visual field $\vec{\oplus}$ defects and cupping of the optic disc sometimes occurred without a raised ocular tension, $\frac{\mathbb{\leftrightarrow}}{\mathbb{\Phi}}$ and added that the optic disc and the visual fields may remain normal for a long time with 2 a high tension in the absence of vascular sclerosis. A vasogenic factor in the causation of 
visual field defects and of changes in the optic disc and optic nerve in glaucoma has been suggested by very many workers (Hayreh, 1970), but there has been much controversy on the vessels involved and the site of the lesion. Most authors consider the involvement of retinal vessels or the arterial circle of Zinn and Haller to be responsible.

Gallois (cited by Lauber, 1936) stated that a sustained increase in intraocular pressure compressed the arteries of the optic disc, thus slowing down the blood flow. Reese and McGavic (1942) stressed the importance of the relationship between the intraocular pressure and the retinal blood pressure in the determination of field loss. Lauber (1936) had also suggested this.

Gafner and Goldmann (1955) described how a rise in intraocular pressure resulted in a reduced blood flow in the laminar region and how a similar change was caused by a fall in pressure in the arteries supplying this region. Niedermeier (1957) described the circulatory disturbances in the region of the arterial circle of Zinn and Haller. Harrington (1959, 1964) suggested that glaucomatous visual field defects were the result of diminished blood flow in the anterior optic nerve in the region of the lamina cribrosa and the circle of Zinn and Haller. According to him this circulatory insufficiency in the anterior optic nerve might be brought about by a number of conditions, one or more of which could upset the normal balance between the intraocular pressure and the retinal or ophthalmic arterial pressure, producing hypoxia in the nerve head and resulting in the characteristic glaucomatous field defects. Hypoxia in the nerve head may be due either to a rise in the intraocular pressure sufficient to overcome normal arterial pressure in the arterioles, or to a fall in the blood pressure in the optic nerve head arterioles, so that a normal or slightly elevated intraocular pressure produces hypoxia in the nerve. The fall in blood pressure may be secondary to arterial insufficiency in the ophthalmic artery and its branches, due for example to carotid artery stenosis or occlusion, to arteriosclerotic plaques in the small arterioles at or behind the lamina cribrosa or on the optic disc, or to embolic phenomena. Similarly, Drance, Wheeler, and Patullo (1968) concluded from their clinical studies that the changes produced in chronic simple glaucoma could be due either to markedly elevated intraocular pressure embarrassing the circulation of the optic nerve head and retina independently of other factors, or to extreme circulatory disturbances with no change in the intraocular pressure. They found a low diastolic blood pressure in all patients who showed marked damage to the optic nerve head or visual field defects.

Our previous studies (Hayreh and Perkins, 1968, I969; Hayreh, 1969) have shown that the ciliary contribution to the optic disc (both from the peripapillary choroid and from the vessels of the underlying lamina cribrosa) is very susceptible to a raised intraocular pressure, to the point of becoming obliterated. The peripapillary choroid was slightly less susceptible than the vessels in the optic disc; this observation has also been recorded by other workers (Gitter, Blumenthal, Galin, and Best, I969, in man; Ernest and Potts, 1968, and David, 1969 , in monkeys). The rest of the choroidal circulation is also susceptible to raised intraocular pressure, though to a smaller extent than the two regions mentioned above. We found no significant defect in the retinal circulation on acute elevation of the intraocular pressure; this contradicts the views of Henkind (1967a, b), Alterman and Henkind (1968), and Kornzweig, Eliasoph, and Feldstein (1968). From our studies it was concluded that, in glaucoma, the primary factor responsible for the visual field defects, optic disc changes, and cavernous degeneration of the optic nerve is the involvement of the choroidal vasculature, especially the peripapillary part thereof and its contribution to the optic disc (Hayreh, I969). 
The present study confirms the previous conclusions (Hayreh and Perkins, 1968, I969; Hayreh, 1969) and shows that the amount of filling of the vessels in the optic disc, peripapillary으․ choroid, and the remainder of the choroid is determined by two factors:

(a) the intraocular pressure;

(b) the blood pressure in the ciliary circulation.

In the present study the systemic arterial pressure was taken as a guide to the ciliaryo blood pressure. In other studies (Hayreh and Edwards, in preparation) on the relation- $\overrightarrow{0}$ ship of the ophthalmic artery pressure and the systemic arterial pressure in rhesus monkeys, $\vec{\exists}$ it was discovered that the systolic blood pressure in the ophthalmic artery normally varied between 69 and 76 per cent. (average 73) of the systemic systolic arterial pressure, and응. that the diastolic pressure in the ophthalmic artery varied between 85 and 96 per cention (average 9o) of the systemic diastolic pressure. Applying these ratios between the systemic and the ophthalmic artery pressures, we can estimate the ophthalmic artery pressure inf the three eyes of the present series in which the systemic arterial pressure was recorded by $\overrightarrow{0}$ cannulating the femoral artery. The filling of the choroid and optic disc at the different? intraocular pressures and the systemic and ophthalmic arterial pressures is shown ine Table II. These results suggest that, when the difference between the systemic diastolic arterial pressure and the intraocular pressure is about $10 \mathrm{~mm}$. $\mathrm{Hg}$ or less, the filling of the $\overrightarrow{0}$ vessels in the optic disc is very poor, being seen only in the temporal sector. When the systemic diastolic pressure is lower than the intraocular pressure, there is no filling of the vessels in the disc or choroid. The exact role of the systolic systemic arterial pressure is not clear but, in an eye in which the difference between systemic systolic pressure and the intraocular pressure was $20 \mathrm{~mm}$. $\mathrm{Hg}$, there was no filling of the choroid and optic disc where there was a difference of 30 to $42 \mathrm{~mm}$. $\mathrm{Hg}$, however, filling of these regions occurred $\stackrel{2}{\vec{t}}$ In the latter two the systemic diastolic pressure was also higher than the intraocular pressure.

It can be concluded from the above observations that a rise in the intraocular pressure. or a fall in the arterial blood pressure has a similar effect on the choroidal, peripapillary $\frac{0}{0}$ and optic disc vessels. The extent of filling of the vessels depends upon the differences between the two: the greater the difference the better the filling, and vice versa. This is well illustrated by the eyes with arterial hypotension described in Tables I and II. AO similar phenomenon was noticed by Harrington (1959) in patients with arterial hyper-0 tension who, on therapeutic lowering of the blood pressure, developed glaucomatous? field defects at normal or slightly raised intraocular pressures, a rise in blood pressure leading to partial recovery. McLean (1957) reported a similar experience. Gafner and心 Goldmann (1955) found a rapid loss of visual field in a case of Addison's disease with arterial hypotension.

In glaucoma, until now, the main emphasis has been placed on raised intraocular pressure, and the management of the condition has been guided solely by the level of the् intraocular pressure. The fact that some patients develop typical glaucomatous visua field defects and optic disc changes at normal intraocular pressures, while others develop? no ocular defects when the pressure is significantly raised has always been puzzling. The present study has shown that two equally important factors determine the outcome in cases of glaucoma; the intraocular pressure and the arterial blood pressure in the choroida $\frac{P}{\mathrm{D}}$ vessels. Although we have satisfactory methods of measuring the intraocular pressure $\frac{\varrho}{\sigma}$ there is as yet no known method of measuring the blood pressure in the choroidal vessels 
Ophthalmodynamometry may give some idea of the blood pressure in the central retinal artery and thus act as an indirect means of estimating the ophthalmic artery pressure, and hence the posterior ciliary artery pressures, though the central retinal artery pressure may not necessarily be a true index of the ciliary or choroidal arterial blood pressure. Moreover, with ophthalmodynamometry, it is not possible to determine absolute values for systolic and diastolic pressures in the retinal arteries. This method only makes possible the comparison of the blood pressures in the two eyes of the same individual, e.g. in unilateral carotid or ophthalmic artery occlusion or stenosis. Alternatively, the systemic arterial blood pressure may be used as a guide to estimating the choroidal arterial blood pressure, though this again is likely to have many drawbacks.

Thus, it is ignorance of the blood pressure in the choroidal and posterior ciliary vessels which makes correct assessment and management of glaucoma a difficult task. The only satisfactory solution would be to correct the imbalance between the intraocular pressure and the blood pressure in the choroidal vessels, instead of being guided by the level of the intraocular pressure alone.

This imbalance also explains the mechanism of so-called "low-tension glaucoma" or "pseudo-glaucoma", which has been a baffling problem. In this condition, instead of a rise in intraocular pressure there is a fall of blood pressure in the ciliary vessels, but the end-results are the same. Another variety of low-tension glaucoma is seen in arteriosclerotic optic atrophy, where a fall in blood pressure in the optic disc and choroidal vessels, caused by arteriosclerotic changes in the posterior ciliary arteries, upsets the normal balance between the intraocular pressure and the blood pressure in the disc and choroidal vessels. A similar phenomenon will result from any factor producing low blood pressure in the ciliary arteries, ophthalmic artery, or carotid artery, e.g. stenosis, occlusion, embolism, or systemic arterial hypotension.

The mechanism of glaucomatous visual field defects, cupping of the optic disc, and cavernous degeneration of the optic nerve is discussed in detail elsewhere (Hayreh, 1969, 1970). The nerve fibre bundle defects and optic disc cupping are due to obliteration of vessels in the prelaminar part of the optic disc and peripapillary choroid. Peripheral constriction of the visual fields and cavernous degeneration of the retrobulbar part of the optic nerve are due to the involvement of the peripheral centripetal vascular system composed of recurrent pial branches from the peripapillary choroid to this part of the optic nerve (see Fig. I, Hayreh, I969). Since the peripapillary choroid supplies both the prelaminar part of the optic disc and retrobulbar part of the optic nerve (Hayreh, I969), its involvement will affect these two regions. The balance between the intraocular pressure and the arterial blood pressure in the choroid, peripapillary choroid, and prelaminar region of the optic disc determines the state of patency of these vessels, and a critical equilibrium exists, particularly in those of the optic disc; lowering of the blood pressure or elevation of the intraocular pressure would have an identical effect.

From these observations, glaucoma may be defined as a disease wherein the normal balance between the intraocular pressure and the blood pressure in the choroidal vessels supplying the optic disc and retrolaminar part of the optic nerve is disturbed, resulting in vascular insufficiency in the optic disc and the retrolaminar part of the optic nerve, and hence in visual field defects and pathological changes in the optic disc and optic nerve.

\section{Summary}

The effect of raised intraocular pressure on the circulation in the choroid and optic disc was studied by fluorescence fundus angiography in eight eyes of cynomolgus monkeys 
after experimental occlusion of the central retinal artery. The findings showed that the balance between the intraocular pressure and the arterial blood pressure in the vessels of the choroid, peripapillary choroid, and prelaminar region of the optic disc determines the state of circulation in these regions. Elevation of the intraocular pressure and lowering of the blood pressure in these vessels have a similar effect. The circulatory disturbances in the optic disc which ensue are responsible for the visual field defects and the optic disc and optic nerve changes in glaucoma.

We are grateful to Prof. E. S. Perkins for providing us with the facilities for this study, to Mrs Anne Roger for secretarial help, and to Mr. Alasdair McDonald for the illustrations.

\section{References}

ALterman, M., and henkind, P. (1968) Brit. 7. Ophthal., 52, 26 DAVID, N. J. (1969) "Proc. Int. Symp. Fluorescein Angiography, Albi". In press DRANCE, S. M., WheEler, C., and PATUllo, M. (1968) Amer. F. Ophthal., 65, $89 \mathrm{r}$ DUKE-ELDER, s. (1953) Ulster med. F., 22, I (1955) "Glaucoma", p. 39. Blackwell Scientific Publications, Oxford

ERNEST, J. T., and POTTS, A. м. (1968) Amer. 7. Ophthal., 66, 380

GAFNER, F., and GOLDMANN, H. (1955) Ophthalmologica (Basel), r30, 357

GitTer, K. A., Blumenthal, M., Galin, M. A., and Best, M. (1969) "Proc. Int. Symp. Fluorescein

Angiography, Albi”, In press

haRrington, D. o. (1959) Amer. F. Ophthal., 47, pt. 2, I 77

- (1964) Trans. Amer. ophthal. Soc., 62, 324

HAYREH, s. s. (1969) Brit. F. Ophthal., 53, 721

(1970) Ibid., 54, 289

and EDWARDS, J. (1970) In preparation

- and PERkins, E. s. (1968) In "The William Mackenzie Centenary Symposium on the

Ocular Circulation in Health and Disease", p. 71. Proc. Symp. Glasgow, September 20-24, 1968. Kimpton, London

- - (1969) “Proc. Int. Symp. Fluorescein Angiography, Albi”. In press

HENKIND, P. (1967a) Brit. 7. Ophthal., 51, 115

(1967b) Invest. Ophthal., 6, 103

KORNZWEig, A. L., EliAsoph, I., and Feldstein, m. (1968) Arch. Ophthal. (Chicago), 80, 696

LAUBER, H. (1936) Ibid., 16, 555

MCLEAN, J. M. (1957) Amer. F. Ophthal., 44, 323

Niedermeier, S. (1957) v. Graefes Arch. Ophthal., 158, 303

REESE, A. B., and McGavic, J. s. (1942) Arch. Ophthal. (Chicago), 27, 845 